\title{
CORRECTIONS
}

\section{Stress at work}

\section{(C) $(\mathcal{Q} \Theta$ OPEN ACCESS}

In an article by Thomas Despréaux and colleagues (BMJ 2017;357:j2489, doi: 10.1136/bmj.j2489), the affiliations for Thomas Despréaux and Alexis Descatha were incorrect. The correct affiliations for these authors are:
Occupational health unit AP-HP (Paris Hospital), University hospital of Poincaré site, Garches, France

Inserm UVSQ (Versailles St-Quentin Univ - Paris Saclay Univ), U1168 - UMS011, Villejuif, France. 